\title{
Diagnostic and prognostic impact of $\beta$-catenin alterations in pediatric liver tumors
}

\author{
HIROAKI YAMAOKA ${ }^{1}$, KAZUHIRO OHTSU ${ }^{4}$, TAIJIRO SUEDA ${ }^{1}$, \\ TAKASHI YOKOYAMA ${ }^{1}$ and EISO HIYAMA ${ }^{2,3}$ \\ ${ }^{1}$ Department of Surgery and ${ }^{2}$ Department of Biomedicine, Graduate School of Biomedical Science, \\ ${ }^{3}$ Natural Science Center of Basic Research and Development, Hiroshima University; \\ ${ }^{4}$ Department of Pediatric Surgery, Hiroshima Prefectural Hospital, Hiroshima, Japan
}

Received October 31, 2005; Accepted November 29, 2005

\begin{abstract}
Hepatoblastoma (HBL), a major childhood malignant neoplasm, represents the most frequent malignant liver tumor in childhood. Recent reports have shown the CTNNB1 coding B-catenin protein to be frequently mutated or deleted at hotspot regions involving exon 3 in HBL. We investigated the genetic alterations of the $C T N N B 1$ coding $\beta$-catenin protein and expression of several genes downstream of Wnt signals in 4 benign and 17 malignant pediatric liver tumors (PLTs) consisting of $15 \mathrm{HBL}, 1$ hepatocellular carcinoma, and 1 hepatic immature sarcoma. Of 17 malignant PLTs, 10 (56\%) revealed pathogenic alterations of the CTNNB1 gene, including 4 with missense mutations at codons $28,32,34$ or 44 , and 6 with interstitial deletions that partially or totally affected exon 3. All 6 deletions were in-frame deletions without a frame shift. The high frequency without any correlation to histological type indicates that the CTNNB1 gene alteration is a crucial event in the tumorigenesis of malignant PLTs. The immunohistochemical studies in 17 malignant PLTs demonstrated the nuclear/cytoplasmic accumulation of $\beta$ catenin to be positive in all tumor specimens except for one hepatic sarcoma. A histological examination revealed all HBL cases involving tumors without detectable CTNNB1 gene alterations to show high expression of $\beta$-catenin, thus indicating the accumulation of $\beta$-catenin to be a common event in malignant PLTs, including HBL and hepatocellular carcinoma. Among the Wnt signal genes downstream of B-catenin, E-cadherin is expressed in all malignant PLTs, while cyclin D1 expression was significantly detected in malignant PLTs with an advanced stage of disease. An immunohistological examination of nuclear accumulation of ß-catenin may thus be useful for diagnosing malignant PLTs.
\end{abstract}

Correspondence to: Dr Eiso Hiyama, Natural Science Center of Basic Research and Development, Hiroshima University, 1-2-3, Kasumi, Minami-ku, Hiroshima 734-8551, Japan

E-mail: eiso@hiroshima-u.ac.jp

Key words: hepatoblastoma, prognosis, ß-catenin, E-cadherin, cyclin D1
On the other hand, the expression of cyclin D1, a gene downstream of $\beta$-catenin, might play a role in tumor progression.

\section{Introduction}

Pediatric liver tumors (PLTs) are common in intra-abdominal tumors in children, and hepatoblastoma (HBL) is one of the most common malignant PLTs with $>70 \%$ of these tumors diagnosed in patients $<2$ years of age (1). HBL tumors, which are derived from hepatic precursor cells, tend to be morphologically similar to immature hepatocytes, but the molecular abnormalities in this tumor have not yet been elucidated (2). The incidence of HBL is significantly high in patients with familiar adenomatous polyposis (FAP) (3-5), who carry germ-line mutations in the APC tumor suppressor gene (6), which encodes a large cytoplasmic protein that plays a role in the Wnt signaling pathway (7). Reports have shown the mutation or deletion of the CTNNB1 gene exon 3 to be frequently detected in HBL, thus suggesting an overactivation of the wingless/WNT signal pathway (8). Moreover, a germline mutation of the Axin gene, which encodes the protein to form a multiprotein complex involving the Wnt signaling, has been reported in cases with HBL (9). As a result, the genesis or progression of HBL involves the abnormal Wnt signaling for the accumulation of $\beta$-catenin, thereby causing nuclear translocation of the B-catenin-Tcf/Lef complex and stimulating transcription of the target genes that include E-cadherin (10), and cyclin D1 (11). To elucidate the role of $\beta$-catenin abnormalities in pediatric liver tumors (PLTs), we searched for alterations of CTNNB1 in PLTs, including HBL tumors and other malignant and benign PLTs, and examined the correlation between these alterations and the expression of $B$-catenin and related genes (E-cadherin and cyclin D1) in these tumors.

\section{Materials and methods}

Patients. A total of 17 patients with pediatric malignant liver tumors (13 males and 4 females; median age, 50 months) underwent a tumor resection and partial hepatectomy between December 1986 and November 2004 at Hiroshima University Hospital and Affiliated institutions. Most patients 
were treated in the JPLT-1 study (12), which consisted of two different protocols: protocol $91 \mathrm{~A}$ for patients with stage I or II hepatoblastoma, and protocol 91B for patients with stage III or IV tumors. In these cases, cases 1-8 were already analyzed for CTNNB1 gene alterations in a series of the JPLT study group (13). Moreover, 4 patients with PLTs involving 1 mesenchymal hamartoma, 1 hemangioma, 1 focal nodular hyperplasia, and 1 regenerative hepatic hyperplasia were also enrolled in this study. These 4 patients underwent surgery only. The Human Ethics Review Committee of Hiroshima University approved the study protocol, and signed informed consent was obtained from each parent (Hiroshima University, Approval of Ethics Committee no. 20).

The clinicopathological parameters and outcomes for these patients were analyzed. The clinical stages of disease were determined at the time of initial biopsy or resection according to the classification of the Japanese Society of Pediatric Surgeons, which was based on the number of liver segments involved, extent of local invasion, extent of regional lymph node involvement, and presence of distant metastases (14). The PRETEXT system is based on hepatic surgical anatomy, which is divided into four sectors, namely an anterior and a posterior sector on the right and a medial and lateral sector on the left (15). Histologically, malignant tumors were classified into $14 \mathrm{HBLs}, 1$ hepatocellular carcinoma (HCC) and 1 immature sarcoma. The pathological classification in hepatoblastoma by Haas et al and the Japanese Society of Pathology $(14,16)$ divide hepatoblastoma into two major subtypes, namely a well-differentiated (fetal) type and a poorly differentiated (embryonal) type.

Tissue samples. Tumor tissue specimens and their corresponding normal liver tissue specimens were obtained during surgery on 21 patients with PLTs, immediately frozen, and stored at $-80^{\circ} \mathrm{C}$ until use. The preparation of DNA was performed by standard proteinase K-phenol-chloroform extraction, as reported previously (17). The tissues were also fixed in formalin and embedded in paraffin for pathological analysis.

Mutation analyses for CTNNB1. For the detection of mutations and deletions of the CTNNB1 gene, genomic DNA derived from each tumor and the corresponding liver tissue was amplified by PCR using a primer pair specific for exon 3. To search for the mutations/deletions in the entire coding region of CTNNB1, PCR was performed using two primer sets. The sequence of the forward primer was 5'-GATTTGATGGAG TTGGACATGG-3' (BCAT-1), and that of the reverse primer was 5'-TGTTCTTGAGTGAAGGACTGAG-3' (BCAT-2) (8). PCR amplification in a reaction mixture containing $1 \mu \mathrm{M}$ each of primer, $200 \mu \mathrm{M}$ dNTPs, $50 \mathrm{mM} \mathrm{KCl}, 10 \mathrm{mM}$ Tris$\mathrm{HCl}(\mathrm{pH} \mathrm{8.3)}, 1.5 \mathrm{mM} \mathrm{MgCl}$, and 1 unit of Taq polymerase (Applied Biosystems) was performed with thermal cycling parameters of $94^{\circ} \mathrm{C}$ for $15 \mathrm{sec}, 60^{\circ} \mathrm{C}$ for $15 \mathrm{sec}$, and $72^{\circ} \mathrm{C}$ for $45 \mathrm{sec}$, for 35 cycles using a thermal cycler (Astek Corp., Fukuoka, Japan). To detect a large deletion including exon 3, the identities of PCR products were analyzed by a $2 \%$ agarose gel or $5 \%$ polyacrylamide gel electrophoresis. To detect the point mutation in exon 3 , the PCR products were reamplified by the internal primers, 5'-AAAATCCAGCGTGGACAA
TGG-3' (BCAT-3) and 5'-TGTGGCAAGTTCTGCATC ATC-3' (BCAT-4). The amplified bands were gel purified on Qiagen columns (Qiagen, Valencia, CA) prior to sequencing with a Sequenase kit (Applied Biosystems, OH), and their nucleotide sequences were determined by DNA sequence analysis using an ABI 3100 sequencer. Mutation identification was confirmed with at least two amplification reactions from the original DNA.

Immunohistochemistry. A mouse monoclonal antibody against ß-catenin (Transduction Lab, Lexington, KY) was used at $5-10 \mu \mathrm{g} / \mathrm{ml}$. The mouse monoclonal antibody E-cadherin (Takara bio Inc., Otsu, Japan) and anti-cyclin D1 antibody (1:500; Santa Cruz Biotechnology, CA) were used at $5-10 \mu \mathrm{g} / \mathrm{ml}$. The tissue specimens were cut into $6-\mu \mathrm{m}$ serial sections. The sections were deparaffinized and rehydrated through ascending grades of alcohol to Trisbuffered saline (TBS), $\mathrm{pH}$ 7.4. Heat-based antigen retrieval was performed as follows: sections were treated for $15 \mathrm{~min}$ in $0.01 \mathrm{M}$ citric acid buffer, $\mathrm{pH} 6.0$ in 2 atmosphere at $120^{\circ} \mathrm{C}$ using an autoclave. After decreasing the pressure, the sections were removed and permitted to cool for approximately $30 \mathrm{~min}$ before being washed 3 times for $5 \mathrm{~min}$ in TBS. Endogenous peroxidase was quenched in $3 \% \mathrm{H}_{2} \mathrm{O}_{2}$. After washing 3 times for $5 \mathrm{~min}$ in TBS, nonspecific antibody binding was blocked by incubating the sections in protein blocking solution (Dako Corp., Carpinteria, CA) for $30 \mathrm{~min}$. The sections were then transferred to a humidified chamber and incubated in antibody solution at $4{ }^{\circ} \mathrm{C}$ overnight. Following this and subsequent incubations, the sections were thoroughly washed in 3 changes of TBS for 5 min each. For immunohistochemical staining, sections were incubated in the labeled streptavidin biotin polymer (Envision Plus; Dako), followed by $0.05 \%$ 3,3'-diaminobenzidine (DAB) or 3\% 3-amino-9-ethyl carbazole (AEC) in TBS with $\mathrm{H}_{2} \mathrm{O}_{2}$ as a substrate. Sections were lightly counterstained with Mayer's hematoxylin, then mounted. The intensity of the immunostaining was evaluated using light microscopy and Image-Pro Plus software version 4 (Media Cybernetics, Silver Spring, MD). The individual signals of tumor specimens were classified into four categories: nucleus-positive (N, IHC signals were strongly detected throughout the nucleus not the nucleolus); cytoplasmic-positive (C; IHC signals were detected in the cytoplasm); membranous-positive (M; IHC signals were detected along the cell membrane); and - (no staining).

Statistical analysis. Statistical analyses were performed using Fisher's test. A p-value $<0.05$ was considered significant.

\section{Results}

Genetic abnormalities in the CTNNB1 gene. Deletion and mutation analyses were performed by focusing on exon 3 of CTNNB1 in 21 pediatric liver tumors, using the standard PCR followed by subsequent DNA sequencing. Of 16 malignant tumors, $10(59 \%)$ had a deletion or mutation (Table I). Deletions ( $n=6)$ were more frequent than the missense mutations $(n=4)$ in HBLs, as reported previously $(8,18,19)$. The interstitial deletions varied from 12 to $659 \mathrm{bp}$, but all of these deletions included the whole or a part of exon 3 . The 
Table I. Clinicopathological parameters, deletion and mutation of the CTNNB1 gene, and immunoreactivity of $\beta$-catenin, E-cadherin, and cyclin D1 in pediatric liver tumors.

\begin{tabular}{|c|c|c|c|c|c|c|c|c|c|}
\hline \multirow[b]{2}{*}{$\begin{array}{c}\text { Case } \\
\text { no. }\end{array}$} & \multirow{2}{*}{$\begin{array}{c}\text { Age } \\
(\mathrm{mo.}) / \\
\text { sex }\end{array}$} & \multirow[b]{2}{*}{ Histology } & \multirow[b]{2}{*}{$\begin{array}{c}\text { Stage }^{a /} \\
\text { PRETEXT }\end{array}$} & \multicolumn{2}{|c|}{$\begin{array}{c}C T N N B 1 \\
\text { gene alterations }\end{array}$} & \multicolumn{3}{|c|}{ Immunohistochemical staining } & \multirow[b]{2}{*}{$\begin{array}{l}\text { Metastasis/ } \\
\text { outcome }\end{array}$} \\
\hline & & & & Deletion & $\begin{array}{l}\text { Mutation } \\
\text { of exon } 3\end{array}$ & $\beta$-catenin & E-cadherin & cyclin D1 & \\
\hline 1 & $42 / \mathrm{M}$ & Poorly & $\mathrm{II} / 2$ & & & $\mathrm{~N}+\mathrm{C}$ & $\mathrm{C}+\mathrm{M}$ & - & Lung $/$ Alive \\
\hline 2 & $6 / \mathrm{M}$ & Poorly & $\mathrm{II} / 2$ & & & $\mathrm{~N}+\mathrm{C}$ & $\mathrm{C}+\mathrm{M}$ & - & -/Alive \\
\hline 3 & $6 / \mathrm{F}$ & Poorly & $\mathrm{I} / 1$ & + & & $\mathrm{N}+\mathrm{C}$ & $\mathrm{C}+\mathrm{M}$ & - & -/Alive \\
\hline 4 & $120 / \mathrm{F}$ & Well & $\mathrm{IIIb} / 4$ & & & $\mathrm{~N}+\mathrm{C}+\mathrm{M}$ & $\mathrm{C}+\mathrm{M}$ & $\mathrm{C}+\mathrm{M}$ & Lung ${ }^{\mathrm{b}} /$ Dead \\
\hline 5 & 19/M & Well & $\mathrm{IIIa} / 3$ & + & & $\mathrm{N}+\mathrm{C}+\mathrm{M}$ & $\mathrm{C}+\mathrm{M}$ & - & -/Alive \\
\hline 6 & $14 / \mathrm{M}$ & Well & $\mathrm{IIIa} / 4$ & & & $\mathrm{~N}+\mathrm{C}+\mathrm{M}$ & $\mathrm{C}+\mathrm{M}$ & $\mathrm{C}$ & Lung $\mathrm{b} / \mathrm{Alive}$ \\
\hline 7 & $120 / \mathrm{M}$ & Well & $\mathrm{IV} / 3$ & & & $\mathrm{~N}+\mathrm{C}+\mathrm{M}$ & - & - & Lung/Alive \\
\hline 8 & $6 / \mathrm{M}$ & Well & $\mathrm{II} / 2$ & + & & $\mathrm{N}+\mathrm{C}$ & $\mathrm{C}+\mathrm{M}$ & - & -/Alive \\
\hline 9 & $10 / \mathrm{M}$ & Well & $\mathrm{I} / 1$ & & + & $\mathrm{N}+\mathrm{C}$ & $\mathrm{C}+\mathrm{M}$ & - & -/Alive \\
\hline 10 & $48 / \mathrm{M}$ & Well & $\mathrm{II} / 2$ & + & & $\mathrm{N}+\mathrm{C}$ & $\mathrm{C}+\mathrm{M}$ & $\mathrm{C}$ & -/Alive \\
\hline 11 & $84 / F$ & Well & $\mathrm{II} / 2$ & & & $\mathrm{~N}+\mathrm{C}+\mathrm{M}$ & $\mathrm{C}+\mathrm{M}$ & - & -/Dead \\
\hline 12 & $144 / \mathrm{M}$ & $\mathrm{HCC}$ & $\mathrm{IIIb} / 4$ & + & & $\mathrm{N}+\mathrm{C}+\mathrm{M}$ & $\mathrm{C}+\mathrm{M}$ & $\mathrm{C}+\mathrm{M}$ & Lung ${ }^{\mathrm{b}} /$ Dead \\
\hline 13 & $18 / \mathrm{F}$ & Pure well & $\mathrm{I} / 1$ & & + & $\mathrm{N}+\mathrm{C}$ & $\mathrm{C}+\mathrm{M}$ & - & -/Alive \\
\hline 14 & $28 / \mathrm{M}$ & Poorly & $\mathrm{IV} / 2$ & & + & $\mathrm{N}+\mathrm{C}+\mathrm{M}$ & $\mathrm{C}+\mathrm{M}$ & $\mathrm{C}+\mathrm{M}$ & -/Alive \\
\hline 15 & 4/M & Immature & $\mathrm{II} / 2$ & & & - & $\mathrm{C}^{\mathrm{c}}+\mathrm{M}$ & - & -/Alive \\
\hline 16 & $132 / \mathrm{M}$ & Well & $\mathrm{IV} / 3$ & + & & $\mathrm{N}+\mathrm{C}$ & $\mathrm{C}+\mathrm{M}$ & $\mathrm{C}$ & $\begin{array}{c}\text { Intra-hepatic }{ }^{\mathrm{b}} / \\
\text { Alive }^{\mathrm{d}}\end{array}$ \\
\hline 17 & $108 / \mathrm{M}$ & Pure well & $\mathrm{I} / 1$ & & + & $\mathrm{N}+\mathrm{C}+\mathrm{M}$ & $\mathrm{C}+\mathrm{M}$ & $\mathrm{C}+\mathrm{M}$ & -/Alive \\
\hline 18 & $0 . / \mathrm{M}$ & $\mathrm{HM}$ & & & & & - & - & -/Alive \\
\hline 19 & $12 / \mathrm{M}$ & HM & & & & & $\mathrm{C}+\mathrm{M}$ & - & -/Alive \\
\hline 20 & $3 / \mathrm{M}$ & $\mathrm{FNH}$ & & & & $\mathrm{C}+\mathrm{M}$ & $\mathrm{C}+\mathrm{M}$ & $\mathrm{C}+\mathrm{M}$ & -/Alive \\
\hline 21 & $11 / \mathrm{M}$ & $\mathrm{RFH}$ & & & & - & - & - & -/Alive \\
\hline
\end{tabular}

N, nuclear; C, cytoplasm; M, membrane; HCC, hepatocellular carcinoma; HM, hemangioma; FNH, focal nodular hyperplasia; RFH, regenerative focal hyperplasia. a Stage classification according to the Japanese Society of Pediatric Surgeons. ${ }^{\text {b}}$ Metastases occurred after surgery; cextremely positive staining in the cytoplasm; and dalive after liver transplantation.

DNA sequence analysis revealed that these mutants were in-frame deletions and might cause the generation of mutant CTNNB1 proteins with a small molecular mass that lacked all or a part of $\mathrm{NH}_{2}$-terminal phosphorylation sites required for their own degradation. On the other hand, the CTNNB1 missense mutations were found in 4 tumors; they were Gly(GGA)34Arg(CGA) (case 9), Gln(ACA)28Pro(ACC) (case 13), Asp(GGA)32Ala(GGC) (case 14), and Pro (CCT) 44His (CAT) (Table I). To examine whether these alterations in the CTNNB1 gene were somatic or germ-line alterations, an analysis using the matched tumor and noncancerous tissue specimens revealed that all of the detected mutations and deletions were somatic (data not shown).

Immunohistochemical analysis. An immunohistochemical analysis of B-catenin expression was performed using 17 malignant PLT tissues, 4 benign PLT tissues and their adjacent normal liver tissues to examine the expression and localization of $\beta$-catenin in the tumor and normal cells. Although the staining pattern of $\beta$-catenin was different and heterogeneous within the tumor specimen, all malignant PLTs except for liver sarcoma showed B-catenin staining in the nuclei and cytoplasm. One negative case was of hepatic sarcoma. In almost all tumor cells, the expression of $ß$-catenin in tumor cells was detected in the nucleus and/or cytoplasm (Fig. 1). Although the staining pattern of ß-catenin was different and heterogeneous within the tumor specimen, the expression of $\beta$-catenin staining in all malignant tumor cells except for liver sarcoma was in the nuclei and cytoplasm. In some PLTs, B-catenin was distributed along the cell membrane. The immunoreactivity of B-catenin in the cell membrane was detected in 8 malignant PLTs $(47 \%)$ including 6 advanced tumors. Staining of the cell membrane was significantly detectable in advanced stages of malignant PLTs $(\mathrm{p}=0.015)$. In 15 hepatoblastoma tissues, $\beta$-catenin staining of the cell membrane was detected in 7 of 11 welldifferentiated (fetal type) tissues and only 1 of 4 embryonal type tissues, but not significantly $(\mathrm{p}=0.244)$ (Fig. 1). No difference was observed in the location of $\beta$-catenin staining between tumors that had mutations or deletions of the 
ß-catenin
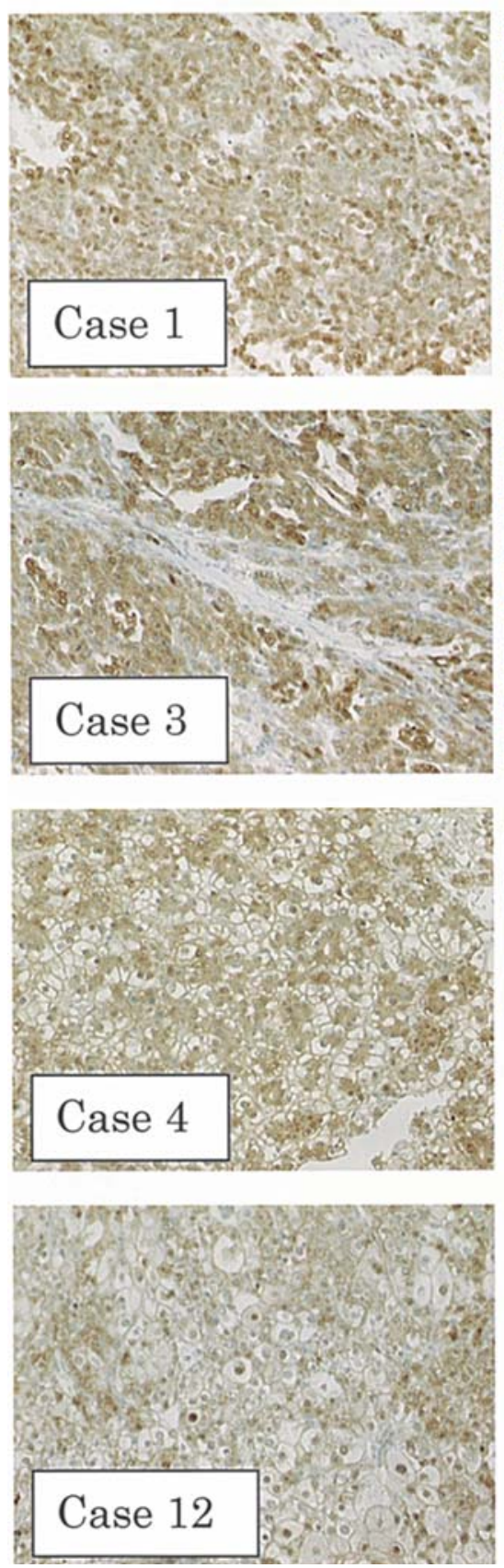

Cyclin D1
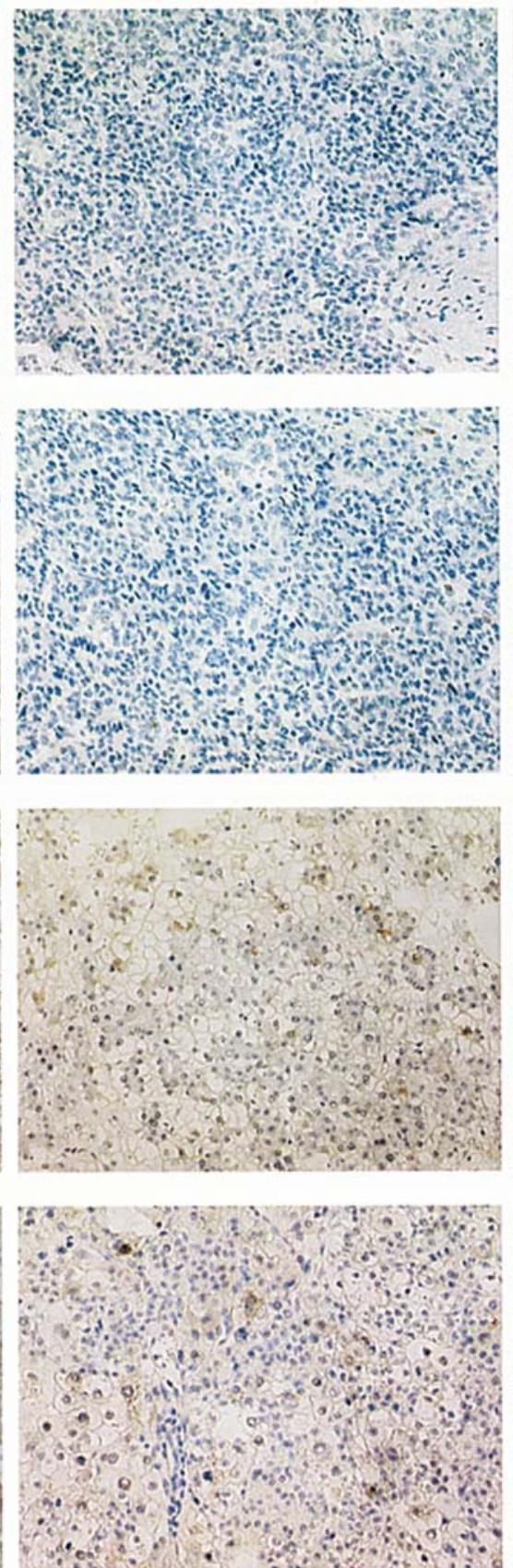

E-cadherin
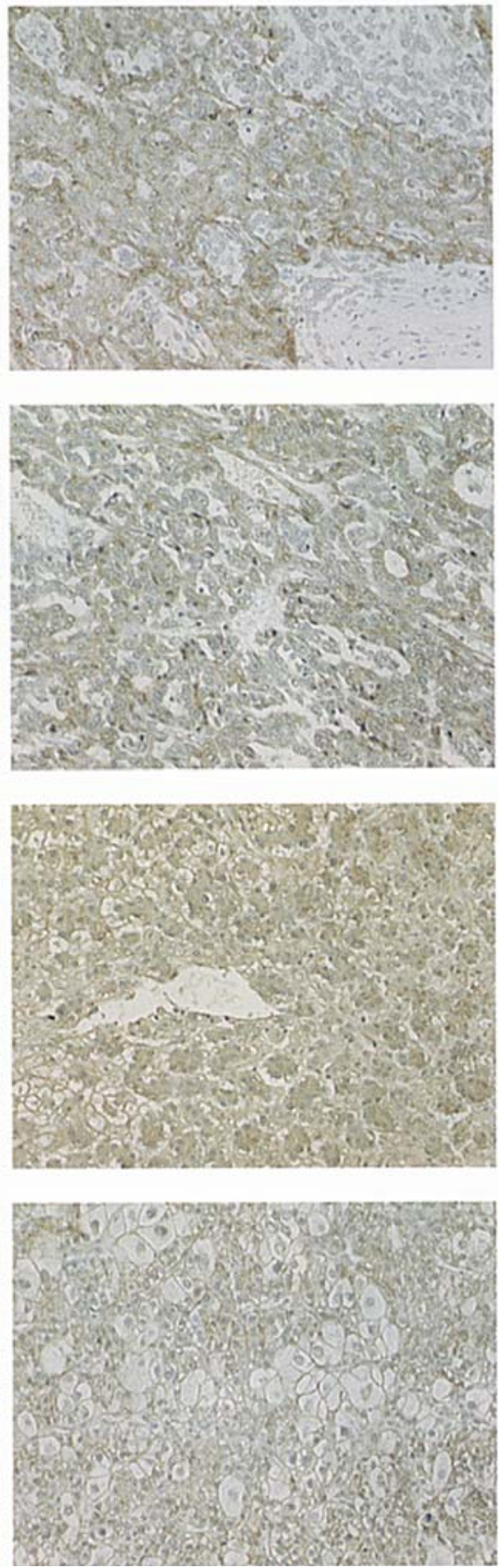

Figure 1. Immunohistochemical analysis of B-catenin, cyclin D1 and E-cadherin expression in malignant pediatric hepatic tumors. Immunoreactivity of ß-catenin was detectable in both the nuclei and cytoplasm of poorly differentiated (cases 1 and 3) and well-differentiated hepatoblastomas (case 4). Hepatocellular carcinoma (case 12) demonstrated B-catenin immnoreactivity in nuclei. Cyclin D1 was detectable in both the nuclei and cytoplasm of cases 4 and 12, but not in cases 1 and 3. E-cadherin was detectable in all cases. As shown in Table I, cases 1 and 12 showed the CTNNB1 gene deletion including exon 3, while cases 3 and 4 did not show detectable CTNNB1 gene alterations. Cases 1 and 3 are alive and disease-free, but cases 4 and 12 died of recurrent disease after surgery. Original magnification, $x 200$.

CTNNB1 gene and other tumors. In the 4 benign PLTs, none showed nuclear staining, whereas 2 benign PLTs showed positive staining in the cytoplasm and cell membrane. In the noncancerous hepatic tissue specimens, no staining was seen in the hepatocyte, while strong staining was seen in epithelial cells of the intrahepatic bile duct.

Immunohistochemical staining of E-cadherin and cyclin D1. An immunohistochemical analysis of E-cadherin and cyclin D1 was performed to examine the expression levels of $ß$-catenin-mediated transactivation of possible target genes. The expression of E-cadherin was detectable in all 17 PLT cells except one case. E-cadherin staining was mainly located in the cytoplasm and cell membrane, but not in the nucleus in almost all malignant PLTs. Certain proteins, including E-cadherin with $\beta$-catenin at the cell membrane, can play a role in carcinogenesis. In hepatic sarcoma, E-cadherin was highly expressed in the tumor cells with no expression of $\beta$-catenin. On the other hand, the expression of cyclin D1 was detected in only 8 of 17 malignant PLT cases. Cyclin D1 
expression was detected in 5 of 6 advanced stages of malignant PLTs and 2 of 10 early stages of PLTs $(p=0.058)$. The death cases showed strong cytoplasmic and membranous staining for cyclin D1. The membranous staining of cyclin D1 was only detected in the tumors with membranous staining for B-catenin. In the benign tumors, both E-cadherin and cyclin D1 were detected in an FNH tumor, but the expression levels of both genes were weaker than those in the $2 \mathrm{HBL}$ cases with positive staining.

The histological types in 15 hepatoblastoma cases included 11 embryonal (well-differentiated) and 4 fetal (poorly differentiated) type tumors. E-cadherin staining was significantly higher in the HBL tissue specimens than the other liver tumor tissue specimens and normal hepatocytes, but it was not significantly higher in the HBL tissues with the CTNNB1 mutation/deletion compared to those without such abnormalities. The elevated expression of cyclin D1 as a target of $\beta$-catenin/TCF/Lef complex in HBL with CTNNB1 mutation was also immunohistochemically confirmed. Two benign tumors, FNH and hamartoma, exhibited cytoplasmic and cell membranous $\beta$-catenin staining, but no nuclear accumulation.

\section{Discussion}

In the present study, we surveyed the alterations of the CTNNB1 gene in 17 PLTs consisting of $15 \mathrm{HBLs}, 1 \mathrm{HCC}$ and 1 hepatic sarcoma. The frequency of CTNNB1 deletions or mutations was substantial (53\%; $9 / 17$ cases), and this percentage was similar to that of German sporadic hepatoblastoma (48\%) (8). Since the Wnt signaling pathway plays an important role in embryonic development, this pathway appears to have a more important role in the tumorigenesis of malignant PLTs, especially HBL. To assess the prevalence of alterations in the Wnt pathway in these tumors, we performed an immunohistochemical analysis of B-catenin and the representative downstream signals, cyclin D1 and cadherin E. Although some heterogeneity of the histological staining within the same section was observed, nuclear and cytoplasmic staining of $\beta$-catenin was detectable in all malignant PLTs except for one hepatic sarcoma. Since the nuclear staining of $\beta$-catenin was undetectable in benign PLTs, the nuclear accumulation of B-catenin may be a useful marker to diagnose malignant PLTs. On the other hand, the cell membranous staining of $\beta$-catenin was detected in 8 of 17 (47\%) malignant PLTs (Fig. 1 and Table I). Statistically, this membranous localization was significantly higher in the advanced stages of the tumors $(p=0.015)$, thus strongly suggesting that the membranous localization of $\beta$-catenin might correlate with the malignant grade of PLTs. The nuclear staining of $B$-catenin without alterations to the CTNNB1 gene suggests that the nuclear accumulation of B-catenin occurs due to abnormalities of other factors in Wnt signals, such as the $A P C$ gene and $A X I N 1$. A high rate of $A P C$ mutations has been reported in Asian hepatoblastoma patients $(61.5 \%)$, and the allelic loss of the $A P C$ gene was found in 7 of $20(35 \%)$ informative cases with $\operatorname{HBL}(8,20)$. The risk of hepatoblastoma in patients with FAP is approximately 847 times higher than that in the general population (21). The APC gene mutation might be one of the mechanisms that stabilize $B$-catenin in HBLs. Moreover, AXIN1 and AXIN2 mutations appear to be important in an additional $10 \%$ of HCCs and HBLs $(9,22)$.

In the Wnt signal downstream genes, E-cadherin was detected in the cytoplasm and cell membrane in almost all malignant PLTs, whereas cyclin D1 was detected in only 7 cases, including 5 advanced cases $(\mathrm{p}=0.0584)$. The membranous staining of cyclin D1 was detected in the tumors with membranous localization of $\beta$-catenin, thus indicating that cyclin D1 may play a role in the tumor progression in malignant PLTs. In hepatic sarcoma, E-cadherin was highly expressed in the cytoplasm of the tumor without $\beta$-catenin accumulation, thus indicating that the overexpression of E-cadherin in hepatic sarcoma might depend on a different pathway except for the Wnt signal.

The hepatic tumor located in the left hepatic lobe of case 17 was first diagnosed as FNH (focal nodular hyperplasia), but a molecular analysis revealed the existence of a CTNNB1 mutation and the nuclear accumulation of B-catenin. As a result, the pathological review of this tumor revealed that final diagnosis of this tumor to be a purely welldifferentiated hepatoblastoma. This result suggested that an analysis of $\beta$-catenin alterations and the nuclear accumulation of $\beta$-catenin may be useful diagnostic tools for distinguishing malignant PLTs from benign FNH tumors.

Immunohistochemical nuclear staining for $\beta$-catenin showed strong positive nuclear staining in all HBLs and one HCC, but a weak signal restricted in the cytoplasm in hepatic sarcoma. In other reports, $\beta$-catenin was overexpressed in almost all cases of HBL $(8,23)$ and $50-83 \%$ of HCCs $(24,25)$. These data suggest that alterations in the Wnt pathway are involved in the pathogenesis of a significant proportion of malignant PLTs, and the nuclear accumulation of $ß$-catenin may be thus a useful marker for an accurate diagnosis of malignant PLTs. Moreover, the cell membranous location of B-catenin and cyclin D1 may be a prognostic factor for malignant PLTs. To clarify the role of cell membranous expression B-catenin and cyclin D1 in malignant PLTs, further research using a greater number of samples is required.

In this study, which investigated the mutational status and expression of the $C T N N B 1$, and expression of $\beta$-catenin, E-cadherin and cyclin D1, the nuclear accumulation of $\beta$-catenin was found in almost all malignant PLTs, including HBLs and $\mathrm{HCC}$, and their roles were discussed in liver carcinogenesis in children. The activation of $\mathrm{Wnt} / \mathrm{B}$-catenin signaling may play a critical role in the carcinogenesis and progression of malignant PLTs including HBL and HCC.

\section{Acknowledgements}

We thank Ms. I. Fukuba and Ms. E. Fukuda for technical assistance. We also wish to thank the Analysis Center of Life Science, Natural Science Center of Basic Research and Development and the Research Center for Molecular Center, Graduate School of Biomedical Science, Hiroshima University, for the use of their facilities.

\section{References}

1. Weinberg AG and Finegold MJ: Primary hepatic tumors of childhood. Hum Pathol 14: 512-537, 1983. 
2. Conran RM, Hitchcock CL, Waclawiw MA, Stocker JT and Ishak KG: Hepatoblastoma: the prognostic significance of histologic type. Pediatr Pathol 12: 167-183, 1992.

3. Yun K, Jinno Y, Sohda T, Niikawa N and Ikeda T: Promoterspecific insulin-like growth factor 2 gene imprinting in human fetal liver and hepatoblastoma. J Pathol 185: 91-98, 1998.

4. Fukuzawa R, Umezawa A, Ochi K, Urano F, Ikeda H and Hata J: High frequency of inactivation of the imprinted $\mathrm{H} 19$ gene in 'sporadic' hepatoblastoma. Int J Cancer 82: 490-497, 1999.

5. Li FP, Thurber WA, Seddon J and Holmes GE: Hepatoblastoma in families with polyposis coli. JAMA 257: 2475-2477, 1987.

6. Kinzler KW and Vogelstein B: Lessons from hereditary colorectal cancer. Cell 87: 159-170, 1996.

7. Ichii S, Horii A, Nakatsuru S, Furuyama J, Utsunomiya J and Nakamura Y: Inactivation of both APC alleles in an early stage of colon adenomas in a patient with familial adenomatous polyposis (FAP). Hum Mol Genet 1: 387-390, 1992.

8. Koch A, Denkhaus D, Albrecht S, Leuschner I, von Schweinitz D and Pietsch T: Childhood hepatoblastomas frequently carry a mutated degradation targeting box of the beta-catenin gene. Cancer Res 59: 269-273, 1999.

9. Miao J, Kusafuka T, Udatsu Y and Okada A: Sequence variants of the Axin gene in hepatoblastoma. Hepatol Res 25: 174-179, 2003.

10. Huber O, Korn R, McLaughlin J, Ohsugi M, Herrmann BG and Kemler R: Nuclear localization of beta-catenin by interaction with transcription factor LEF-1. Mech Dev 59: 3-10, 1996.

11. Tetsu $\mathrm{O}$ and McCormick F: Beta-catenin regulates expression of cyclin D1 in colon carcinoma cells. Nature 398: 422-426, 1999.

12. Sasaki F, Matsunaga T, Iwafuchi M, Hayashi Y, Ohkawa H, Ohira M, Okamatsu T, Sugito T, Tsuchida Y, Toyosaka A, Nagahara N, Nishihira H, Hata Y, Uchino J, Misugi K and Ohnuma N: Outcome of hepatoblastoma treated with the JPLT1 (Japanese Study Group for Pediatric Liver Tumor) Protocol-1: A report from the Japanese Study Group for Pediatric Liver Tumor. J Pediatr Surg 37: 851-856, 2002.

13. Takayasu H, Horie H, Hiyama E, Matsunaga T, Hayashi Y, Watanabe Y, Suita S, Kaneko M, Sasaki F, Hashizume K, Ozaki T, Furuuchi K, Tada M, Ohnuma N and Nakagawara A: Frequent deletions and mutations of the beta-catenin gene are associated with overexpression of cyclin D1 and fibronectin and poorly differentiated histology in childhood hepatoblastoma. Clin Cancer Res 7: 901-908, 2001.

14. Hata Y: The clinical features and prognosis of hepatoblastoma: follow-up studies done on pediatric tumors enrolled in the Japanese Pediatric Tumor Registry between 1971 and 1980. Part I. Committee of Malignant Tumors, Japanese Society of Pediatric Surgeons. Jpn J Surg 20: 498-502, 1990.
15. Brown J, Perilongo G, Shafford E, Keeling J, Pritchard J, Brock P, Dicks-Mireaux C, Phillips A, Vos A and Plaschkes J: Pretreatment prognostic factors for children with hepatoblastoma - results from the International Society of Paediatric Oncology (SIOP) study SIOPEL 1. Eur J Cancer 36: 1418-1425, 2000.

16. Haas JE, Muczynski KA, Krailo M, Ablin A, Land V, Vietti TJ and Hammond GD: Histopathology and prognosis in childhood hepatoblastoma and hepatocarcinoma. Cancer 64: 1082-1095, 1989.

17. Sambrook A, Fritish EF and Maniatis T: Molecular Cloning. A Laboratory Manual. 2nd edition. Cold Spring Harbor Laboratory, Cold Spring Harbor, NY, pp914-919, 1989.

18. Anna CH, Sills RC, Foley JF, Stockton PS, Ton TV and Devereux TR: Beta-catenin mutations and protein accumulation in all hepatoblastomas examined from $\mathrm{B} 6 \mathrm{C} 3 \mathrm{~F} 1$ mice treated with anthraquinone or oxazepam. Cancer Res 60: 2864-2868, 2000.

19. Udatsu Y, Kusafuka T, Kuroda S, Miao J and Okada A: High frequency of beta-catenin mutations in hepatoblastoma. Pediatr Surg Int 17: 508-512, 2001.

20. Park WS, Oh RR, Park JY, Kim PJ, Shin MS, Lee JH, Kim HS, Lee SH, Kim SY, Park YG, An WG, Kim HS, Jang JJ, Yoo NJ and Lee JY: Nuclear localization of beta-catenin is an important prognostic factor in hepatoblastoma. J Pathol 193: 483-490, 2001.

21. Giardiello FM, Offerhaus GJ, Krush AJ, Booker SV, Tersmette AC, Mulder JW, Kelley CN and Hamilton SR: Risk of hepatoblastoma in familial adenomatous polyposis. J Pediatr 119: 766-768, 1991

22. Anna CH, Iida M, Sills RC and Devereux TR: Expression of potential beta-catenin targets, cyclin D1, c-Jun, c-Myc, E-cadherin, and EGFR in chemically induced hepatocellular neoplasms from B6C3F1 mice. Toxicol Appl Pharmacol 190: 135-145, 2003.

23. Jeng YM, Wu MZ, Mao TL, Chang MH and Hsu HC: Somatic mutations of beta-catenin play a crucial role in the tumorigenesis of sporadic hepatoblastoma. Cancer Lett 152: 45-51, 2000.

24. Ihara A, Koizumi H, Hashizume R and Uchikoshi T: Expression of epithelial cadherin and alpha- and beta-catenins in nontumoral livers and hepatocellular carcinomas. Hepatology 23: 1441-1447, 1996.

25. Huang H, Fujii H, Sankila A, Mahler-Araujo BM, Matsuda M, Cathomas $\mathrm{G}$ and Ohgaki H: Beta-catenin mutations are frequent in human hepatocellular carcinomas associated with hepatitis $C$ virus infection. Am J Pathol 155: 1795-1801, 1999. 